\title{
Prevalence and determinants of extrinsic origin dental erosion among children and adolescents from Wrocław
}

\section{Występowanie i uwarunkowania zewnątrzpochodnych erozji szkliwa u dzieci i młodzieży z Wrocławia}

\author{
Katarzyna Harłukowicz ${ }^{B}$, Urszula Kaczmarek ${ }^{A, C-F}$ \\ Department of Conservative Dentistry and Pedodontics, Wroclaw Medical University, Poland \\ A - research concept and design; $\mathrm{B}$ - collection and/or assembly of data; $\mathrm{C}$ - data analysis and interpretation; \\ $D$ - writing the article; $E$ - critical revision of the article; $F$ - final approval of the article
}

\author{
Address for correspondence \\ Urszula Kaczmarek \\ E-mail: urszula.kaczmarek@umed.wroc.pl

\section{Funding sources} \\ None declared \\ Conflict of interest \\ None declared

\section{Acknowledgments} \\ Project ST - 800, “Dental erosion in children and adolescents \\ - prevalence and determinants", financed by Wroclaw Medical \\ University.
}

Received on 0ctober 22, 2017

Reviewed on November 8, 2017

Accepted on November 22, 2017

\begin{abstract}
Background. The results of studies have revealed some increase of dental erosion prevalence; however, the data concerning the prevalence of erosive lesions in a Polish population is scarce.

Objectives. To evaluate frequency and severity of dental erosion in children and adolescents.

Material and methods. A total of 240 subjects of both sexes, aged 12 to 18 years, living in Wrockaw were examined and surveyed. Erosive lesions were assessed with the use of indices by Lussi, O'Sullivan and BEWE. A questionnaire consisting of 33 parameters related to oral hygiene and dietetic habits was used. The data obtained was analyzed in reference to the frequency, severity and location of dental erosion.

Results. The frequency of dental erosion was 16.25\%; it was slightly higher in boys than girls and significantly higher in lower compared to upper teeth. The indices used identified the same number of erosion-affected teeth but not their severity due to different descriptive criteria. However, the erosive lesions were mostly limited to enamel and located in lower molar teeth. The mean cumulative BEWE score was $2.23 \pm 1.42$, which could place the subjects into a low dental erosion risk group. The development of erosive lesions was significantly correlated with intake of cola, energy/sports drinks and other carbonated beverages, as well as acidic food and bananas.

Conclusions. Dental erosion could become a more important problem of dental health among children and adolescents due to the frequent consumption of acidic beverages and food. Therefore, there is a need to promote awareness in dentists to make an early diagnosis and to assess the dietetic factors conducive to the development of erosive lesions.
\end{abstract}

Key words: dental erosion, prevalence, children, adolescents

Słowa kluczowe: erozja zębów, rozpowszechnienie, dzieci, młodzież

DOI

$10.17219 / \mathrm{dmp} / 80735$

Copyright

○ 2017 by Wroclaw Medical University

and Polish Dental Society

This is an article distributed under the terms of the

Creative Commons Attribution Non-Commercial License

(http://creativecommons.org/licenses/by-nc-nd/4.0/) 
According to the Consensus Report of the European Federation of Conservative Dentistry (EFCD) from 2015, dental erosion, named as erosive tooth wear (ETW), is a chemical-mechanical process resulting from cumulative loss of hard dental tissues, which is not caused by bacteria and characterized by loss of the natural morphology and contour of the teeth. ETW is a multifactorial lesion with acids as the prevailing cause. ${ }^{1}$ Acids causing dental erosion can be of extrinsic origin (mostly from food and beverages as well as from some oral medicines) or intrinsic origin (chronic vomiting, acidic gastroesophageal reflux disease), or environmental, related to vocational exposure to acids. However, the development and severity of dental erosion is a sequel of the simultaneous interaction, lasting for an appropriate time, of various chemical, biological and behavioral factors, as well as a general health condition. ${ }^{1-3}$ Among the acidic extrinsic factors, the most essential is nutrition which is based on frequent and large consumption of acidic food (fresh fruits, especially citrus, vegetables and processed products) and beverages (fruit juices and flavored carbonated and still drinks), and their pattern of consumption. The erosive potential of nutrition is influenced, not only by $\mathrm{pH}$ levels but also the acid type and concentration, titratable acidity, and content of calcium and phosphates, which can reduce the erosive effect. Citric acid, being a flavor-enhancer in a great number of food products, also has a chelative effect and forms calcium complexes. Likewise, frequent and long-term orally-taken medicines in a liquid, lozenge or chewing tablet form containing ascorbic acid (vitamin C) or acetylsalicylic acid (Aspirin), and inhaled medicines used for asthma treatment (low $\mathrm{pH}$, reduction of salivary secretion) have an impact on the risk of dental erosion development. ${ }^{3-6}$

The initial signs of erosion are sometimes difficult to detect, as they manifest by loss of surface texture (perikimata), localized silky and shiny area, sometimes dull dental surface, flattening of occlusal surface and formation of rounded dimples. More advanced lesions present shallow and wide or fissurated concavities, rounded cusps, on the facial surface a rim of intact enamel along the gingival margin (due to buffering of acids by sulcus fluid), and exposed or shimmered dentin through the thinned enamel. In the later stage, the whole occlusal morphology disappears, exposing the deeper part of the dentin, restoration can stand out of the adjacent dental surface and dentin hypersensitivity can occur. ${ }^{1,6}$

Other types of tooth wear due to physical (mechanical) loss of hard dental tissues are attrition, abrasion and abfraction. However, in clinical conditions, most tooth wear lesions are a combination of dental wear processes in which one of them plays a dominant role.

Clinical differentiation of erosive lesions from other types of tooth wear is based on manifestation and causative behavioral factors. Attrition presents flat shiny areas with clear margins on the occlusal surface and cor- responding lesions on antagonistic teeth. Abrasion produces deep but not wide lesions with sharp edges on a smooth surface. It is mainly caused by traumatic toothbrushing. Abfraction leads to wedge-shaped lesions at the cervical region with depth clearly exceeding width and sharp margins. The lesion is observed on a single tooth or non-adjacent teeth. Loss of dental structure is hypothesized to be a result of eccentrically applied occlusal forces generating tensile and compressive forces leading to tooth flexure and breakage of the enamel and dentin. ${ }^{7-8}$

The aim of the study was to determine the frequency and severity of dental erosion among children and youth living in Wrocław, Poland.

\section{Material and methods}

A total of 240 children and adolescents (92 males and 148 females) aged $12(\mathrm{n}=71), 15(\mathrm{n}=75)$ and 18 years ( $\mathrm{n}=94)$, randomly selected, were involved in the clinical and questionnaire study. The inclusive criteria were as follows: completed 12, 15 and 18 years of age, no chronic systemic diseases, completed questionnaire, written informed consent of a parent for 12- and 15-year olds, written informed consent completed by 18-year olds, and readiness to cooperate. Dental erosion was assessed with the use of 3 indices: the index developed by Lussi, the one developed by O'Sullivan and the Basic Erosive Wear Examination - BEWE. ${ }^{9-11}$ Clinical examination was carried out with use of a ball-end explorer (WHO 621) under an artificial light.

The index developed by Lussi separately categorizes lesions located on facial and oral/occlusal surfaces. ${ }^{9}$ Grading on facial surfaces is as follows: grade 0 - no erosion; grade 1 - concavity in enamel more wide than deep without involvement of dentin, cervically to the lesion an intact rim enamel; grade 2 - exposure of dentin less than $50 \%$ of the dental surface; grade 3 - exposure of dentin more than $50 \%$ of the dental surface. In contrast, grading of oral/occlusal surfaces is as follows: grade $0-$ no erosion; grade 1 - slight erosion, rounded cusps, edges of restoration protruding out of the level of adjacent dental surface, grooves on occlusal surface, loss of enamel without dentin exposure; grade 2 - severe erosion, more advanced signs than in grade 1 and with dentin exposure. The data was presented as frequency of occurrence of the particular categories of erosion severity in the subjects.

The dental erosion index described by O'Sullivan is based on a grade of severity of the lesions. ${ }^{10}$ Codes are as follows: 0 - normal enamel; 1 - matt appearance of enamel surface without loss of contour; 2 - loss of enamel only (loss of surface contour); 3 - loss of enamel with dentin exposure (dentin-enamel junction visible); 4 - loss of enamel and dentin beyond dentin-enamel junction; 5 - loss of enamel and dentin with pulp exposure; 9 - unable to assess (for example due to large restoration, crowned tooth), location 
on each tooth surface (codes: A - labial or buccal only; B - lingual or palatal only; C - occlusal or incisal only; D labial and incisal/occlusal; $\mathrm{E}$ - lingual and incisal/occlusal; $\mathrm{F}$ - multi-surface) and area dimension of the lesion on the affected surface (codes: - less than half; + more than half of the affected surface).

BEWE index evaluates the lesions on all dental surfaces. ${ }^{11}$ All teeth in sextants, except $3^{\text {th }}$ molars, are assessed, but only the surface with the highest score in each sextant is recorded. The total BEWE score (cumulative score) is a sum of the scores in 6 sextants. Scores for the diagnosis of erosion are as follows: 0 - sound tooth; 1 - initial loss of surface texture; 2 - clear loss of hard dental tissues with less than $50 \%$ of the surface area affected, dentin is often exposed; 3 - pronounced loss of hard dental tissues with more than $50 \%$ of the surface area and dentin often exposed. Based on the cumulative score of all sextants, the BEWE index also assesses a level of erosion risk and provides management procedures. The risk level of dental erosion is "none" when the total score is less than or equal to 2, "low" between 3 and 8, "medium" between 9 and 13, and "high" for a score of 14 and over. The data and erosion risk level in the affected subjects were presented in aspect of distribution and seventy of erosive lesions.

The questionnaire survey was comprised of parameters referring to oral hygiene (frequency, duration and time of tooth brushing, brushing teeth immediately after intake of acidic food and beverages, type of toothbrush used - hard, medium, soft, electric powered, usage of fluoridated or nonfluoridated dentifrice) and dietetic habits (frequency of consumption of orange, apple or vegetable juices, carbonated and noncarbonated beverages, beverages with vitamin C, cocoa, milk, yogurt, herbal tea, oranges, apples, bananas, ketchup, mustard, vinegar dressing, sauerkraut, pickles), usage of chewing gum and use of a swimming pool. In the paper, only parameters showing a significant relationship with dental erosion were presented.
Statistical analysis of the data obtained was conducted with use of STATISTICA v. 12 PL (StatSoft, Inc., Tulsa, Oklahoma, USA) and Microsoft Excel spreadsheet using descriptive statistics, giving ranks for questionnaire replies. The hypothesis regarding no correlation with specified features was estimated with use of Pearson's $\chi^{2}$ test with Yates correction or Fisher's exact test of independence and Spearman's rank correlation coefficient at significance level of $\mathrm{p}<0.05$.

The approval of the Bioethics Committee of the Wroclaw Medical University for the study was obtained (KB291/2013).

\section{Results}

Frequency of dental erosion in all subjects amounted to $16.2 \%$, and it was only slightly higher in boys compared to girls (18.5\% vs $14.9 \%)$. Significantly more frequently the erosive lesions were present in lower teeth than in upper ones (Table 1). Even though a higher prevalence of the lesions was observed along with age $(12.7 \%$ at the age of $12,14.7 \%$ at the age of 15 , and $20.2 \%$ at the age of 18), the differences were statistically insignificant. Only 3 subjects had lesions occurring simultaneously in both jaws (Table 2). Among all subjects, erosive lesions affected 86 teeth, which constituted $1.31 \%$ of present teeth in the oral cavity (86/6559). On the average, 2.2 teeth were affected by erosion.

According to the index reported by Lussi, more lesions restricted to the enamel or involving enamel and dentin were located on occlusal surfaces than facial ones $(81.39 \%$ or $11.63 \%$ vs $6.98 \%) .{ }^{9}$ Moreover, some lesions on occlusal surfaces already exposed the dentin (11.63\%). We did not find any lesions located on the lingual surface of the teeth (Table 3).

Table 1. Frequency of dental erosion in all subjects

\begin{tabular}{|c|c|c|c|c|c|c|c|}
\hline \multirow{2}{*}{$\begin{array}{l}\text { Frequency } \\
\text { of erosive lesions }\end{array}$} & \multicolumn{2}{|c|}{ All subjects $(n=240)$} & \multicolumn{2}{|c|}{ Female $(n=148)$} & \multicolumn{2}{|c|}{ Male $(n=92)$} & \multirow{2}{*}{$\begin{array}{c}\text { Pearson's } \chi^{2} \text { test } \\
\text { with Yates correction }\end{array}$} \\
\hline & $n$ & $\%$ & $\mathrm{n}$ & $\%$ & $n$ & $\%$ & \\
\hline Whole dentition & 39 & 16.25 & 22 & 14.86 & 17 & 18.47 & $p=0.577$ \\
\hline Maxilla & 12 & $5.00^{\mathrm{a}}$ & 8 & 5.40 & 3 & 3.26 & $p=0.951$ \\
\hline Mandible & 30 & $12.50^{\mathrm{a}}$ & 15 & 10.13 & 16 & 17.39 & $p=0.422$ \\
\hline
\end{tabular}

Significant difference between ${ }^{\mathrm{a}-\mathrm{a}}$ at $\mathrm{p}<0.01$ level.

Table 2. Frequency of dental erosion in age groups of subjects in reference to the whole dentition, and upper and lower teeth

\begin{tabular}{|c|c|c|c|c|c|c|c|}
\hline \multirow{3}{*}{$\begin{array}{l}\text { Frequency } \\
\text { of erosive lesions }\end{array}$} & \multicolumn{6}{|c|}{ Age } & \multirow{3}{*}{$\begin{array}{c}\text { Pearson's } \chi^{2} \text { test } \\
\text { with Yates correction }\end{array}$} \\
\hline & \multicolumn{2}{|c|}{$12(n=71)$} & \multicolumn{2}{|c|}{$15(n=75)$} & \multicolumn{2}{|c|}{$18(n=94)$} & \\
\hline & $n$ & $\%$ & $n$ & $\%$ & $n$ & $\%$ & \\
\hline Whole dentition & 9 & 12.67 & 11 & 14.67 & 19 & 20.21 & $p=0.389$ \\
\hline Maxilla & 2 & 2.81 & 2 & 2.67 & 8 & 8.51 & $p=0.135$ \\
\hline Mandible & 7 & 9.86 & 9 & 12.00 & 14 & 14.89 & $p=0.722$ \\
\hline
\end{tabular}


Table 3. Grading of dental erosion according to the erosion index by Lussi in the whole dentition of all subjects

\begin{tabular}{|c|c|c|c|c|}
\hline & Grade & & $\mathrm{n} / \mathrm{N}$ & $\%$ \\
\hline \multirow{3}{*}{$\begin{array}{l}\text { Facial } \\
\text { surfaces }\end{array}$} & 1 & concavity in enamel more wider than deep without involvement of dentin, cervically to the lesion intact enamel & $6 / 86$ & $6.98^{\mathrm{a}}$ \\
\hline & 2 & exposure of dentin less than $1 / 2$ of the dental surface & 0 & 0 \\
\hline & 3 & exposure of dentin more than $1 / 2$ of the dental surface & 0 & 0 \\
\hline \multirow{2}{*}{$\begin{array}{l}\text { Occlusal } \\
\text { surfaces }\end{array}$} & 1 & $\begin{array}{l}\text { slight erosion, rounded cusps, edges of restorations protruding out of the level of adjacent dental surface, } \\
\text { grooves on occlusal surfaces, loss enamel without dentin exposure }\end{array}$ & $70 / 86$ & $81.39^{\mathrm{ab}}$ \\
\hline & 2 & severe erosion, more advanced signs than in grade 1 with dentin exposure & 10/86 & $11.63^{b}$ \\
\hline
\end{tabular}

Significant difference between ${ }^{a-a},{ }^{b-b}$ at $p<0.01$ level (Fisher's exact test of independence).

Based on the index developed by O'Sullivan, $72.1 \%$ of all affected teeth revealed erosion limited to the enamel, and the rest of them exposed the dentin. ${ }^{10}$ Most of the erosive lesions were located on the occlusal surface $(81.39 \%)$ and less of them on the labial/buccal surface (4.65\%). More than 1 dental surface involved by the lesion was noticed in 3 subjects. Over half of the teeth presented the lesion area involving less than half of the dental surface (Table 4).

The dental erosion assessment with the use of the BEWE index showed that the lesions occurred almost symmetrically in posterior sextants of the maxilla and mandible, but most often in the $4^{\text {th }}$ and $6^{\text {th }}$ sextants. In a few subjects, the erosive lesions affected upper anterior teeth, while lower anterior teeth were untouched (Fig. 1). The mean value of the BEWE cumulative score was $2.23 \pm 1.42$ (median 2), which could categorize the subjects in the group with low risk level of dental erosion.

The values of correlation coefficients between the potential erosion-associated factors and location of erosive lesions on dental surfaces categorized according to the indices of Lussi and O'Sullivan, as well as in sextants in accordance with the BEWE index are presented in Table 5. ${ }^{9,10}$ Some differentiation of the significant correlations was noticed, which probably resulted from the different descriptive criteria of the indices. Generalizing, one could find the correlation of erosion occurrence

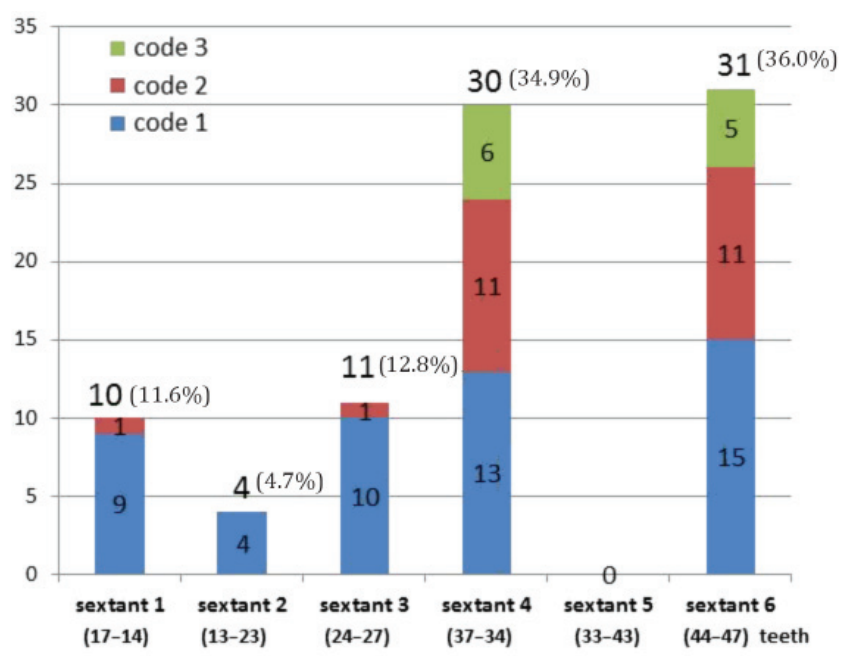

Fig. 1. Distribution of dental erosion in sextants according to BEWE index

on labial/buccal surfaces with the consumption at least once a day of acidic vegetables and bananas (the last one only based upon the evaluation according to the index by Lussi). ${ }^{9}$ In contrast, the presence of the lesions on occlusal surfaces was correlated with tooth brushing immediately after intake of acidic food, consumption at least once a day of cola, other carbonated and energy/sports beverages, acidic vegetables and ketchup (the last one

Table 4. Severity of erosive lesions according to the erosion index by O'Sullivan in the whole dentition of all subjects

\begin{tabular}{|c|c|c|c|c|c|}
\hline \multirow{2}{*}{ Lesion severity } & \multicolumn{2}{|c|}{ Whole dentition } & \multirow{2}{*}{ Lesion location on dental surface } & \multicolumn{2}{|c|}{ Whole dentition } \\
\hline & $\mathrm{n} / \mathrm{N}$ & $\%$ & & $\mathrm{n} / \mathrm{N}$ & $\%$ \\
\hline $\begin{array}{l}\text { Code 1: matt appearance of the enamel surface } \\
\text { without of loss of contour }\end{array}$ & $16 / 86$ & 18.60 & Code A: labial or buccal & $4 / 86$ & $4.65^{a}$ \\
\hline Code 2: loss of enamel only & $46 / 86$ & 53.50 & Code B: lingual or palatal & \multicolumn{2}{|l|}{0} \\
\hline $\begin{array}{l}\text { Code } 3 \text { : loss of enamel with dentin-enamel } \\
\text { junction visible }\end{array}$ & $16 / 86$ & 18.60 & Code C: occlusal or incisal & $70 / 86$ & $81.39^{a, b, c}$ \\
\hline $\begin{array}{l}\text { Code 4: loss of enamel and dentin beyond } \\
\text { dentin-enamel junction }\end{array}$ & $8 / 86$ & 9.30 & Code D: labial and incisal/occlusal & $9 / 86$ & $10.46^{b}$ \\
\hline $\begin{array}{l}\text { Code 5: loss of enamel and dentin with the pulp } \\
\text { exposure }\end{array}$ & \multicolumn{2}{|l|}{0} & Code E: lingual and incisal/occlusal & \multicolumn{2}{|l|}{0} \\
\hline Code 9: unable to assess & \multicolumn{2}{|l|}{0} & Code F: multi- surface & \multirow{2}{*}{\multicolumn{2}{|c|}{$\begin{array}{c}3 / 86 \quad 3.50^{c} \\
\text { All lesions }\end{array}$}} \\
\hline Area of surface affected by erosion & \multicolumn{2}{|c|}{ All lesions } & Area of surface affected by erosion & & \\
\hline$<50 \%$ & $48 / 86$ & 55.81 & $>50 \%$ & $38 / 86$ & 44.19 \\
\hline
\end{tabular}

Significant difference between ${ }^{a-a}, b^{b-b}, c-c$ at $p<0.01$ level (Fisher's exact test of independence). 
Table 5. Values of Spearman's rank correlation coefficients (rho) between components of erosion indices and hygienic and dietetic parameters

\begin{tabular}{|c|c|c|c|c|c|c|c|}
\hline \multirow{3}{*}{ Parameter } & \multirow{2}{*}{\multicolumn{2}{|c|}{$\frac{\text { Erosion index by Lussi }^{9}}{\text { dental surface }}$}} & \multirow{2}{*}{\multicolumn{2}{|c|}{\begin{tabular}{|c|} 
Erosion index by O'Sullivan ${ }^{10}$ \\
location: dental surface
\end{tabular}}} & \multicolumn{3}{|c|}{ BEWE erosion index } \\
\hline & & & & & \multicolumn{3}{|c|}{ Sextants } \\
\hline & facial & occlusal & C: occlusal & $\begin{array}{l}\text { D: labial and } \\
\text { occlusal }\end{array}$ & $\begin{array}{c}2 \text { teeth } \\
13-23\end{array}$ & $\begin{array}{l}4 \text { teeth } \\
37-34\end{array}$ & $\begin{array}{l}6 \text { teeth } \\
44-47\end{array}$ \\
\hline $\begin{array}{l}\text { Frequency of brushing teeth immediately } \\
\text { after consumption of acidic food* }\end{array}$ & $\begin{aligned} \mathrm{rho} & =-0.010 \\
\mathrm{p} & =0.383\end{aligned}$ & $\begin{array}{r}r h o=0.168 \\
p=0.010\end{array}$ & $\begin{array}{r}r h o=0.146 \\
p=0.024\end{array}$ & $\begin{aligned} \mathrm{rho} & =-0.010 \\
\mathrm{p} & =0.873\end{aligned}$ & $\begin{aligned} \mathrm{rho} & =-0.010 \\
\mathrm{p} & =0.873\end{aligned}$ & $\begin{aligned} \mathrm{rho} & =-0.010 \\
\mathrm{p} & =0.873\end{aligned}$ & $\begin{aligned} \text { rho } & =0.106 \\
p & =0.101\end{aligned}$ \\
\hline Frequency drinking of cola** & $\begin{aligned} \text { rho } & =-0.031 \\
p & =0.637\end{aligned}$ & $\begin{array}{r}r h o=0.171 \\
p=0.008\end{array}$ & $\begin{array}{r}r h o=0.141 \\
p=0.030\end{array}$ & $\begin{aligned} \mathrm{rho} & =-0.031 \\
\mathrm{p} & =0.637\end{aligned}$ & $\begin{aligned} \text { rho } & =-0.031 \\
p & =0.637\end{aligned}$ & $\begin{aligned} r h o & =0.177 \\
p & =0.006\end{aligned}$ & $\begin{array}{r}r h o=0.097 \\
p=0.134\end{array}$ \\
\hline $\begin{array}{l}\text { Frequency drinking of energy/sport } \\
\text { beverages** }\end{array}$ & $\begin{aligned} \text { rho } & =-0.013 \\
p & =0.836\end{aligned}$ & $\begin{aligned} \text { rho } & =0.218 \\
p & =0.001\end{aligned}$ & $\begin{array}{r}r h o=0.197 \\
p=0.002\end{array}$ & $\begin{aligned} \mathrm{rho} & =-0.013 \\
\mathrm{p} & =0.836\end{aligned}$ & $\begin{aligned} \mathrm{rho} & =-0.013 \\
\mathrm{p} & =0.836\end{aligned}$ & $\begin{aligned} \text { rho } & =0.149 \\
p & =0.021\end{aligned}$ & $\begin{aligned} r h o & =0.156 \\
p & =0.016\end{aligned}$ \\
\hline $\begin{array}{l}\text { Frequency drinking of carbonated } \\
\text { beverages** }\end{array}$ & $\begin{aligned} r h o & =0.064 \\
p & =0.326\end{aligned}$ & $\begin{aligned} r h o & =0.052 \\
p & =0.420\end{aligned}$ & $\begin{array}{r}\text { rho }=0.072 \\
p=0.265\end{array}$ & $\begin{aligned} r h o & =0.064 \\
p & =0.326\end{aligned}$ & $\begin{aligned} r h o & =0.174 \\
p & =0.007\end{aligned}$ & $\begin{aligned} \text { rho } & =0.028 \\
p & =0.671\end{aligned}$ & $\begin{aligned} r h o & =0.053 \\
p & =0.415\end{aligned}$ \\
\hline $\begin{array}{l}\text { Frequency consumption of acidic } \\
\text { vegetables }^{* *}\end{array}$ & $\begin{aligned} r h o & =0.498 \\
p & =0.001\end{aligned}$ & $\begin{aligned} r h o & =0.262 \\
p & =0.001\end{aligned}$ & $\begin{aligned} r h o & =0.226 \\
p & =0.001\end{aligned}$ & $\begin{aligned} r h o & =0.498 \\
p & <0.001\end{aligned}$ & $\begin{aligned} \mathrm{rho} & =-0.008 \\
\mathrm{p} & =0.897\end{aligned}$ & $\begin{aligned} \text { rho } & =0.266 \\
p & <0.001\end{aligned}$ & $\begin{aligned} r h o & =0.288 \\
p & <0.001\end{aligned}$ \\
\hline Frequency consumption of ketchup** & $\begin{aligned} \mathrm{rho} & =-0.043 \\
\mathrm{p} & =0.508\end{aligned}$ & $\begin{aligned} r h o & =0.087 \\
p & =0.177\end{aligned}$ & $\begin{array}{r}r h o=0.144 \\
p=0.026\end{array}$ & $\begin{aligned} \mathrm{rho} & =-0.043 \\
\mathrm{p} & =0.508\end{aligned}$ & $\begin{aligned} r h o & =-0.043 \\
p & =0.508\end{aligned}$ & $\begin{aligned} r h o & =0.070 \\
p & =0.279\end{aligned}$ & $\begin{array}{r}r h o=0.094 \\
p=0.148\end{array}$ \\
\hline Frequency consumption of bananas** & $\begin{aligned} r h o & =0.135 \\
p & =0.036\end{aligned}$ & $\begin{aligned} \mathrm{rho} & =-0.026 \\
\mathrm{p} & =0.691\end{aligned}$ & $\begin{aligned} \mathrm{rho} & =-0.055 \\
\mathrm{p} & =0.398\end{aligned}$ & $\begin{array}{l}\text { rho }=-0.058 \\
p=0.373\end{array}$ & $\begin{aligned} \mathrm{rho} & =-0.058 \\
\mathrm{p} & =0.373\end{aligned}$ & $\begin{aligned} r h o & =-0.057 \\
p & =0.379\end{aligned}$ & $\begin{aligned} r h o & =-0.029 \\
p & =0.649\end{aligned}$ \\
\hline
\end{tabular}

* - never or sometimes vs always, ** - once a week, once a month or less than once a month vs at least once a day or more.

only based upon the evaluation with use of the index by O'Sullivan). ${ }^{10}$ In turn, according to the BEWE index, erosion occurrence in anterior upper teeth was correlated with the consumption of bananas and in posterior lower teeth with the drinking of energy/sports beverages and consumption of acidic vegetables, and only in teeth from the $4^{\text {th }}$ sextant with the drinking of carbonated beverages.

\section{Discussion}

The prevalence of dental erosion in permanent teeth among children and adolescents is highly differentiated in different countries. It ranges from 5.5 to $65.34 \%$; at the age of 12 years from 13 to $56.1 \%$, at the age of 15 years from 24 to $44.2 \%$, and at the age of 18 years from 22.2 to $55.5 \%{ }^{12-18}$ Moreover, a comparison of the data from the literature regarding frequency and severity of dental erosion is hindered by the use of various scoring systems (e.g., the Eccles index, Tooth Wear index by Smith and Knight, Simplified-Tooth Wear Index, Evaluating Index of Dental Erosion, index by O’Brien, index by Lussi, index by O'Sullivan and BEWE scoring system). ${ }^{19,20}$ In Polish youth, erosive lesions occurred at close to the same rate as those reported in the literature, aged 15 years $24.7 \%$ and aged 18 years $42.3 \%$ (evaluation according to the BEWE index). ${ }^{21,22}$ However, among adolescents aged 15 years living in the Lower Silesia region (including Wrocław), the frequency of dental erosion was higher than in Poland generally (36.1\% vs $24.7 \%) .{ }^{23}$ Our data indicated a lower frequency of dental erosion among children and adolescents from Wrocław aged 12-18 years: $16.2 \%$ (at the age of 12 years $-12.7 \%$, at the age of 15 years $-14.7 \%$, and at the age of 18 years $-20.2 \%$ ). The observed increase of dental erosion frequency along with the age of the subjects was noticed in previously published papers. ${ }^{13,18}$ It probably resulted from longer time of the teeth's presence in the oral environment and longer exposure onto erosive factors. An earlier study performed in 12-year-olds from Wrocław with use of the index by Lussi showed lower than the current erosion frequency $(8.3 \%$ vs $12.7 \%)$, which could suggest a progressive increase of this pathology. ${ }^{24}$

A more frequent occurrence of erosive lesions in males compared to females was found by Arnadottir et al. and McGuire et al., and in our study the same tendency was also noticed ( $18.47 \%$ vs $14.86 \%$, respectively). ${ }^{25,26}$

All of the indices used in our study identified the same number of erosion-affected teeth but not their severity; according to the index by Lussi, the lesions limited only to the enamel involved 76 teeth, and 10 teeth with lesions exposing the dentin, whereas in accordance with the criteria of the index by O'Sullivan, there were 62 and 24 affected teeth, respectively. A similar inconsistency regarding the severity of erosive lesions and, moreover, differences in frequency was reported by Margaritis et al., who, for dental erosion assessment, simultaneously used 3 indices - the BEWE, Simplified Tooth Wear Index (STWI) and Evaluating Index of Dental Erosion (EVIDE). ${ }^{27}$ Therefore, a comparison of the data requires taking into account the diagnostic criteria of the indices used or to apply a commonly accepted index. The European Federation of Conservative Dentistry recommends as a suitable index for classification of dental erosion the BEWE, which links the grading of lesions with clinical management. ${ }^{1,9}$ In our study, the erosive lesions classified in accordance with the BEWE revealed that the most frequently affected were lower molars and mainly the lesions were restricted to the enamel. The BEWE cumulative score calculated per all affected subjects was 
$2.23 \pm 1.42$, which could place the subjects in the group with a low risk level of dental erosion. At this risk level, the recommended clinical management is based on the following procedures: oral hygiene and dietary assessment, advice, routine maintenance and observation repeated at 2-year intervals. ${ }^{9}$

Studies have shown a significant relationship between the prevalence of dental erosion and the frequency and quantity of acidic beverages drunk by children and adolescents. ${ }^{13,15,16}$ Dugmore and Rock evaluated the nutritional habits of subjects from Great Britain at the age of 12 and again at the age of 14 years. ${ }^{15}$ They showed that the consumption of carbonated beverages among the subjects aged 12 years caused a 1.46-fold increase of erosion risk and among the subjects aged 14 years the erosion risk was 2.21 times higher. When the consumption of these beverages was 4 or more times a day, a significantly higher risk was observed, 2.23-fold for those aged 12 years and 5.13-fold higher for those aged 14 years. However, intake of other fruits than citrus or apples caused little risk of erosion development. Al-Dlaigan et al., studying British adolescents at the age of 14 years found a significant positive correlation between the frequency of erosive lesions on the buccal/lingual dental surfaces with the drinking of carbonated and noncarbonated beverages and energy drinks and consumption of fresh fruits (apples, oranges, bananas, grapes), as well as intake of tablets with vitamin $C .{ }^{28}$ In turn, Okunseri et al. found some increase of dental erosion prevalence along with frequency of drinking apple juice among 13-19-year-olds from the USA. ${ }^{13}$ Hasselkvist et al. also observed a significant correlation of dental erosion prevalence with soft drink intake among 13-14-year-olds and 18-19-year-olds from Sweden. ${ }^{18}$ Our results have confirmed the previously reported links between nutritional habits and dental erosion development. They also indicate that, at least once a day, drinking cola, carbonated beverages or energy/sports drinks and consumption of pickled vegetables, ketchup and bananas was significantly related with dental erosion development. Bananas are perceived, in general, as sweet fruits, however their $\mathrm{pH}$ is in the acidic range (from 4.50 to 5.20$).{ }^{29}$ A relationship between dental erosion and declared tooth brushing directly after intake of acidic foods also was found in our study. In such situations, the enamel softened by dietetic acid is easily lost due to less resistance to the abrasive influence of the toothbrush and dentifrice.

Preventive management against dental erosion is directed to diminish or arrest lesion progression and therapeutic procedures to restore the loss of hard dental tissues and elimination of dentin hypersensitivity, if present, in connection with preventive measures.

The present study had a limitation because of the relatively small sample of the subjects. More research should be done to determine the main risk factors of the development of dental erosion in the young population.

\section{Conclusions}

The frequency of dental erosion in children and adolescents aged 12 to 18 years was $16.25 \%$. Mostly, the erosive lesions were limited to the enamel and located on lower molar teeth. The subjects revealed low dental erosion risk according to the BEWE criteria. The occurrence of erosive lesions was significantly correlated with drinking cola, energy drinks and other carbonated beverages as well as consumption of acidic food and bananas. Dental erosion can become a more important problem of oral health among children and adolescents due to frequent consumption of acidic beverages and food. Therefore, there is a need to promote awareness in dentists to make an early diagnosis and to assess the dietetic factors promoting to development of erosive lesions.

\section{References}

1. Carvalho TS, Colon P, Ganss C, et al. Consensus Report of the European Federation of Conservative Dentistry: Erosive tooth wear Diagnosis and management. Swiss Dent J. 2016;126:342-346.

2. Bartlett D. Intrinsic causes of erosion. Monogr Oral Sci. 2006;20:119-139.

3. Lussi A. Erosive tooth wear - A multifactorial condition of growing concern and increasing knowledge. Monogr Oral Sci. 2006;20:1-8.

4. Hellwig $E$, Lussi A. Oral hygiene products and acidic medicine. Monogr Oral Sci. 2006;20:112-118.

5. Thomas MS, Parolia A, Kundabala M, Vikram M. Asthma and oral health: A review. Aust Dent J. 2010;55:128-133.

6. Addy M, Shellis RP. Interaction between attrition, abrasion and erosion in tooth wear. In: Lussi A, ed. Dental erosion: From diagnosis to therapy. Basel: Karger;2006:17-31.

7. Ganss C, Lussi A. Diagnosis of erosive wear. Monogr Oral Sci. 2006;20:32-43.

8. Imfeld T. Dental erosion. Definition, classification and links. Eur J Oral Sci. 1996;104:151-155.

9. Lussi A. Dental erosion. Clinical diagnosis and case history taking. Eur J Oral Sci. 1996;104:191-198.

10. O'Sullivan EA. A new index for the measurement of erosion in children. Eur J Paediatr Dent. 2000;1:69-74.

11. Bartlett D, Ganss C, Lussi A. Basic Erosive Wear Examination (BEWE): A new scoring system for scientific and clinical needs. Clin Oral Invest. 2008;12(Suppl. 1):59-63.

12. Mungia R, Zarzabal LA, Dang SC, Baez M, Stookey GK, Brown JP. Epidemiologic survey of erosive tooth wear in San Antonio, Texas. Tex Dent J. 2009;126:1097-1109.

13. Okunseri C, Okunseri E, Gonzalez C, Visotcky A, Szabo A. Erosive tooth wear and consumption of beverages among children in the United States. Caries Res. 2011;45:130-135.

14. Peres KG, Armênio MF, Peres MA, Traebert J, De Lacerda JT. Dental erosion in 12-year-old schoolchildren: A cross-sectional study in Southern Brazil. Int J Paediatr Dent. 2005;15:249-255.

15. Dugmore CR, Rock WP. The prevalence of tooth erosion in 12-yearold children. Br Dent J. 2004;196:279-282.

16. El Aidi H, Bronkhorst EM, Huysmans MC, Truin GJ. Dynamics of tooth erosion in adolescents: A 3-year longitudinal study. J Dent. 2010;38:131-137.

17. Gurgel CV, Rios D, Buzalaf MA, et al. Dental erosion in a group of 12and 16-year-old Brazilian schoolchildren. Pediatr Dent. 2011;33:23-28.

18. Hasselkvist A, Johansson A, Johansson AK. Dental erosion and soft drink consumption in Swedish children and adolescents and the development of a simplified erosion partial recording system. Swed Dent J. 2010;34:187-195.

19. Lopez-Frias FJ, Castellanos-Costanes L, Martin-Gonzales J, LlamasCarreras JM, Segura-Egea J. Clinical measurement of tooth wear: Tooth wear indices. J Clin Exp Dent. 2012;4:e48-e53.

20. Bardsley PF. The evolution of tooth wear indices. Clin Oral Investig. 2008;12(Suppl. 1):15-19. 
21. Wierzbicka M, Szatko F, Strużycka I, et al. Monitoring of oral health Oral health condition and its determinants, and preventive-therapeutic needs of children at age 5, 7 and 15. Poland 2011. ISBN 97883-7637-115-3 [in Polish].

22. Wierzbicka M, Szatko F, Strużycka I, et al. Monitoring of oral health. Oral health condition and its determinants, and preventive-therapeutic needs of children at age 6 and 12 and adolescents at age 18 . Poland 2012. ISBN 978-83-7637-205-1 [in Polish].

23. Kaczmarek U, Czajczyńska-Waszkiewicz A, Składnik-Jankowska J. Prevalence of dental erosion in 15-year-old subjects from Lower Silesia province. J Stoma. 2012;65:359-369.

24. Kaczmarek U, Woźniak J, Sołtan E, Wilk-Sieczak B, Sommer-Szelepin E. Nutritional and oral hygienic habits in children with dental erosion. Przeg/ Stomat Wieku Rozwoj. 2001;1:22-25 [in Polish].

25. Arnadottir IB, Holbrook WP, Eggertsson $\mathrm{H}$, et al. Prevalence of dental erosion in children: A national survey. Community Dent Oral Epidemiol. 2010;38:521-526.

26. McGuire J, Szabo A, Jackson S, Bradley TG, Okunseri C. Erosive tooth wear among children in the United States: Relationship to race/ethnicity and obesity. Int J Paediatr Dent. 2009;19:91-98.

27. Margaritis V, Mamai-Homata $\mathrm{E}$, Koletsi-Kounari $\mathrm{H}$, Polychronopoulou A. Evaluation of three different scoring systems for dental erosion: A comparative study in adolescents. J Dent. 2011;39:88-93.

28. Al-Dlaigan $\mathrm{YH}$, Shaw L, Smith A. Dental erosion in a group of British 14-year-old school children. Part II: Influence of dietary intake. Br Dent J. 2001;190:258-261.

29. UW Food Safety and Health: $\mathrm{pH}$ values of common foods and ingredients: https://foodsafety.wisc.edu/business_food/files/Approximate_pH.pdf. Accessed December 3, 2017. 
